\title{
Educational and interactive informed consent process for treatment of unruptured intracranial aneurysms
}

\author{
Jaechan Park, MD, PhD, ${ }^{1,2}$ Wonsoo Son, MD, 1,2 Ki-Su Park, MD,,2 Dong-Hun Kang, MD,,2 \\ Joomi Lee, PhD, ${ }^{3}$ Chang Wan Oh, MD, PhD, ${ }^{4}$ O-Ki Kwon, MD, PhD, ${ }^{4}$ Taesun Kim, MD, PhD, ${ }^{5}$ and \\ Chang-Hyun Kim, MD ${ }^{6}$
}

${ }^{1}$ Department of Neurosurgery, ${ }^{2}$ Research Center for Neurosurgical Robotic Systems, and ${ }^{3}$ Cell \& Matrix Research Institute, Kyungpook National University, Daegu; ${ }^{4}$ Department of Neurosurgery, Seoul National University College of Medicine, Seoul; ${ }^{5}$ Department of Neurosurgery, Chonnam National University Medical School, Gwangju; and ${ }^{6}$ Department of Neurosurgery, Keimyung University School of Medicine, Daegu, Republic of Korea

OBJECTIVE For patients with unruptured intracranial aneurysms (UIAs), the information transfer that precedes informed consent needs to be in-depth and detailed, as most patients with a UIA have no symptoms, yet the risks related to treatment are relatively high. Thus, in this study an educational and interactive program was proposed for patients with UIAs to improve the informed consent process and assess the level of comprehension.

METHODS A total of 110 patients with UIAs underwent the proposed educational and interactive informed consent (EIIC) process and were enrolled in this study. The EIIC process combines patient education using information booklets, a cartoon book, a video, an initial physician-patient interview, answering a questionnaire, a second physician-patient interview based on the questionnaire results, and finally consent. After the first physician-patient interview that provides the patient with specific information, including his or her angiographic characteristics, medical condition, and recommended treatment, the patient is requested to answer a questionnaire composed of 3 parts: demographic information, including the patient's age, sex, and years of education; 13 medical questions to assess the patient's knowledge about his or her UIA; and an evaluation of the usefulness of the educational resources. The control group consisted of $65 \mathrm{pa}-$ tients from 3 other tertiary university hospitals where the EIIC process was not used.

RESULTS The questionnaire scores of the EIIC group ranged from 7 to 13 (mean \pm SD: $11.9 \pm 1.3$ ) and were significantly higher than those for the controls $(10.2 \pm 1.9, p<0.001)$. The better comprehension of the patients in the EIIC group was remarkable as they were significantly older than those in the control group $(62.7 \pm 8.3$ years vs $55.9 \pm 10.5$ years, respectively; $p<0.001$ ). For both the ElIC group and the control group, a Pearson correlation analysis revealed a positive correlation ( $r=0.232$ for the ElIC group, $r=0.603$ for controls) between the years of education and the questionnaire score ( $p=0.015$ for the EIIC group, $p<0.001$ for the controls), whereas no correlation was found between the patient age and the questionnaire score. For the ElIC group, the verbal information from the attending physician was selected by 90 patients $(81.8 \%)$ as the most useful and informative educational method, while the most effective reinforcement of this verbal communication was the video $(n=86 ; 78.2 \%)$, information booklets $(n=16 ; 14.5 \%)$, the Internet $(n=7 ; 6.4 \%)$, and the cartoon book $(n=1 ; 0.9 \%)$.

CONCLUSIONS The proposed standardized EIIC process resulted in good patient comprehension about UIAs. The verbal information from the attending physician was the most informative, and the video was the most effective reinforcement of the verbal communication. The patient level of comprehension was shown to be correlated with years of education.

https://thejns.org/doi/abs/10.3171/2016.2.JNS151830

KEY WORDS endovascular; informed consent; intracranial aneurysm; questionnaire; vascular disorders

ABBREVIATIONS EIIC = educational and interactive informed consent; $M C A=$ middle cerebral artery; UIA $=$ unruptured intracranial aneurysm.

SUBMITTED August 5, 2015. ACCEPTED February 18, 2016.

INCLUDE WHEN CITING Published online May 6, 2016; DOI: 10.3171/2016.2.JNS151830. 
$\mathrm{W}$ ITH the significant improvement of diagnostic imaging, including MR and CT angiography, the incidence of UIA diagnosis has dramatically increased, along with the incidence of surgical and endovascular treatment. However, the impact of more and more cases of UIA treatment means the health care system is assuming many of the features of an assembly line, none of which enhance patient autonomy.

Informed consent is a key process in achieving patient autonomy and participation in medical decision making, and indeed a fundamental tenet of surgical practice in medicolegal matters. ${ }^{5,10,20}$ In particular, for patients with UIAs, the information transfer preceding the signing of consent needs to be in-depth and detailed, as most patients with a UIA have no symptoms, yet the treatment risks are relatively high.

However, while the quality of the informed consent process has received increasing attention in the neurosurgical field, previous studies have only investigated generalized informed consent processes occurring before such neurosurgical procedures as intracranial and spinal surgeries..$^{15,16}$ Therefore, because the information transfer process for informed consent needs to be both educational and interactive in nature, this study presents an educational program for patients with UIAs to improve the informed consent process and uses a questionnaire to examine and enhance the patient's level of comprehension.

\section{Methods}

\section{Patient Population}

The proposed educational and interactive informed consent (EIIC) model was implemented at Kyungpook National University Hospital, while the control group was obtained through 3 other tertiary university hospitals (Seoul National University Bundang Hospital, Chonnam National University Hospital, and Dongsan Medical Center) where the proposed standardized multifaceted consent process was not used.

All the patients in this prospective study completed a questionnaire assessing their level of comprehension after the informed consent process for microsurgical clipping or endovascular coiling of a UIA. The inclusion criteria were patients $>18$ years of age, the diagnosis of a UIA based on catheter angiography, and the ability to read and understand the written booklets and questionnaire. The exclusion criteria included patients with a hearing impairment, giant aneurysms with a diameter $>2.5 \mathrm{~cm}$, fusiform aneurysms, and cases of impending rupture (e.g., posterior communicating artery aneurysms inducing oculomotor nerve palsy). This study was reviewed and approved by an institutional ethics committee.

\section{EIIC Processes}

Most patients underwent catheter angiography to evaluate the exact size, shape, and location of the UIA with the related vasculature and to determine the radiographic projections for endovascular coiling. The patient EIIC process was initiated during bed rest following catheter angiography, while the patients who brought an angiogram from another hospital started the education process when they visited our outpatient clinic.

A standardized sequence was implemented, including patient education using various educational materials, an initial physician-patient interview, answering a questionnaire, a second physician-patient interview based on the questionnaire results, and finally consent. The patients were given 3 information booklets and a cartoon book with the following titles: 1) "Ruptured Intracranial Aneurysms" (booklet, 12 pages), 2) "Microsurgical Clipping for UIAs" (booklet, 13 pages), 3) "Endovascular Coiling for UIAs" (booklet, 25 pages), and 4) "Intracranial Aneurysms" (cartoon book, 21 pages). The booklets were all written by the current authors, and the cartoon book was created based on the 3 booklets.

After reading the written education materials, the patients were also asked to watch a video covering the following 3 topics: ruptured intracranial aneurysms (10 minutes), microsurgical clipping for UIAs (10 minutes), and endovascular coiling for UIAs (20 minutes). The current authors participated in the production of the video and all the written education materials.

The ensuing first physician-patient interview, taking 10-20 minutes, covered general information about the UIA, specific information based on the angiographic characteristics and medical condition of the individual patient, and the recommended treatment. The treatment recommendation was determined in advance on a case-by-case basis by the neurovascular surgeon (J.P.) and endovascular interventionist (D.H.K.), one of whom then conducted the physician-patient interview.

If an aneurysm was amenable to either surgical or endovascular treatment, both treatments were discussed with the patient, although endovascular coiling was primarily recommended. For those patients requiring observation, the patient interview was conducted by the physician linked to the future procedure in the case of aneurysmal change (i.e., a neurosurgeon for middle cerebral artery [MCA] aneurysms and an endovascular interventionist for paraclinoid aneurysms). If there was a case of disagreement between the neurosurgeon and the interventionist, both treatment options were equally presented to the patient by the physician in charge.

The educational materials and interview were intended to allow the patients to understand their condition, their prognosis without treatment, the recommended treatment with the attendant risks and benefits, and reasonable alternatives. The patients then returned home and were encouraged to seek information from other sources, including the Internet. For the final treatment decision, a second physician-patient interview was arranged at the outpatient clinic 1-2 weeks later.

\section{Questionnaire}

When visiting the outpatient clinic for the second physician-patient interview, the patients were first asked to complete a questionnaire composed of 3 parts (Table 1): 1) demographic information, including the patient's age, sex, and years of education; 2) medical questions to assess the patients' understanding of their UIA; and 3) an evaluation of the usefulness of the provided educational resources. 
TABLE 1. UIA Questionnaire

\begin{tabular}{|c|c|c|c|}
\hline \multirow[t]{3}{*}{ Part 1} & \multicolumn{3}{|l|}{ Age ( ) } \\
\hline & \multicolumn{3}{|l|}{ Gender ( ) } \\
\hline & \multicolumn{3}{|l|}{ Years of education ( ) } \\
\hline & Category & Question & $\begin{array}{l}\text { Correct } \\
\text { Answer }\end{array}$ \\
\hline \multirow[t]{13}{*}{ Part 2} & \multirow[t]{3}{*}{ Pathophysiology } & $\begin{array}{l}\text { 1. An aneurysm is a balloon-like bulge in a cerebral artery caused by a weakness in the arterial wall, } \\
\text { usually where it branches. It takes several years to develop. }\end{array}$ & Agree \\
\hline & & $\begin{array}{l}\text { 2. Aneurysms can burst and bleed into the brain, causing serious complications including hemor- } \\
\text { rhagic stroke, permanent nerve damage, disability, or death. }\end{array}$ & Agree \\
\hline & & 3. Most cerebral aneurysms do not produce symptoms until they either rupture or become very large. & Agree \\
\hline & \multirow[t]{3}{*}{ Treatment indications } & 4. Not all cerebral aneurysms need to be treated due to the risk of procedure-related complications. & Agree \\
\hline & & $\begin{array}{l}\text { 5. Aneurysm treatment, surgical or endovascular, is recommended if the risk of aneurysm rupture is } \\
\text { considered significant based on the size, shape, and location of the aneurysm. }\end{array}$ & Agree \\
\hline & & $\begin{array}{l}\text { 6. If a patient desires aneurysm treatment due to severe anxiety resulting from harboring a UIA, surgi- } \\
\text { cal or endovascular treatment can be applied. }\end{array}$ & Agree \\
\hline & \multirow{3}{*}{$\begin{array}{l}\text { Treatment modalities and } \\
\quad \text { alternatives }\end{array}$} & 7. The treatment of a UIA always starts with medical treatment. & Disagree \\
\hline & & $\begin{array}{l}\text { 8. Two treatment options, surgical clipping or endovascular coiling, are available for treating cerebral } \\
\text { aneurysms. }\end{array}$ & Agree \\
\hline & & $\begin{array}{l}\text { 9. If the aneurysm is not treated, yearly angiographic examinations using CTA or MRA are recom- } \\
\text { mended for life to detect any changes to the aneurysm. }\end{array}$ & Agree \\
\hline & Procedural risks & $\begin{array}{l}\text { 10. Aneurysm surgery itself carries significant risks for the patient. For unruptured non-giant anterior } \\
\text { circulation aneurysms, the procedure-related mortality is about } 1 \% \text {, while the major morbidity af- } \\
\text { fecting daily life due to hemiparesis, mental deterioration, and speech problems is about } 2 \% \text {. }\end{array}$ & Agree \\
\hline & \multirow[t]{2}{*}{ Other management } & 11. Patients with a UIA should stop smoking. & Agree \\
\hline & & 12. Patients with a UIA should control hypertension. & Agree \\
\hline & Treatment results & $\begin{array}{l}\text { 13. After aneurysm treatment, a cerebral aneurysm can recur at the previous aneurysm site or develop } \\
\text { de novo at another site. }\end{array}$ & Agree \\
\hline \multirow[t]{2}{*}{ Part 3} & $\begin{array}{l}\text { Indicate the most useful } \\
\text { educational resources }\end{array}$ & \multicolumn{2}{|l|}{$\begin{array}{l}\text { Information booklets, cartoon book, video, verbal information from physicians (attending physician, fellow, resi- } \\
\text { dent), Internet }\end{array}$} \\
\hline & $\begin{array}{l}\text { Indicate the most effective } \\
\text { reinforcement of the } \\
\text { verbal communication }\end{array}$ & Information booklets, cartoon book, video, Internet & \\
\hline
\end{tabular}

CTA = computed tomography angiography; MRA = magnetic resonance angiography.

For the medical questions, the patients were asked to agree or disagree with 13 questions about the pathophysiology, treatment indications, available treatment modalities with alternatives, procedural risks, other management, and treatment results for UIAs. The 13 questions were designed to assess the patient's level of comprehension of his or her medical condition, and the results provided a focus for additional education during the second physicianpatient interview. The medical question data were analyzed by calculating the scores, where each correct answer scored 1 point.

To evaluate the relative contribution of the educational materials in providing an understanding of UIAs, the patients were asked to rank the usefulness of the different educational methods: information booklets, cartoon book, video, Internet, and verbal information from the attending physician.

After using the results of the medical questions to provide additional information to the patient during the second physician-patient interview, the final treatment deci- sion was confirmed, and the treatment schedule given to the patient.

\section{Statistical Analysis}

The statistical analyses were performed with the aid of commercially available statistical software (SPSS version 19.0, IBM Inc.). In this case-control comparison, a t-test was used for the quantitative variables (age, years of education, and questionnaire score), while a chi-square analysis was used for the categorical variable (sex). In addition, a Pearson correlation analysis was used to investigate the relationship between the questionnaire score and the related variables (age and years of education). The results were considered significant for probability values less than 0.05 .

\section{Results \\ Patients}

A total of 110 patients with UIAs went through the proposed EIIC process, where the conditions included a 
TABLE 2. Comparison of patients who went through the EIIC process and the control group

\begin{tabular}{lccr}
\hline \multicolumn{1}{c}{ Variable } & $\begin{array}{c}\text { ElIC Group } \\
(\mathrm{n}=110)\end{array}$ & $\begin{array}{c}\text { Control Group } \\
(\mathrm{n}=65)\end{array}$ & $\mathrm{p} \mathrm{Valu \textrm {e } ^ { * }}$ \\
\hline Mean age \pm SD $(\mathrm{yrs})$ & $62.7 \pm 8.3$ & $55.9 \pm 10.5$ & $<0.001 \dagger$ \\
\hline Sex $(\%)$ & & & $0.417 \ddagger$ \\
\hline Male & $44(40.0)$ & $22(33.8)$ & \\
\hline Female & $66(60.0)$ & $43(66.2)$ & \\
\hline $\begin{array}{l}\text { Mean years of education } \pm \\
\quad \text { SD (yrs) }\end{array}$ & $11.5 \pm 3.4$ & $11.6 \pm 3.7$ & $0.869 \dagger$ \\
\hline Mean questionnaire score \pm SD & $11.9 \pm 1.3$ & $10.2 \pm 1.9$ & $<0.001 \dagger$ \\
\hline
\end{tabular}

* Boldface type indicates statistical significance.

t The t-test was used.

$\ddagger$ The chi-square test was used.

single UIA at the internal carotid artery $(\mathrm{n}=24)$, anterior cerebral artery $(n=28)$, MCA $(n=45)$, and vertebrobasilar artery $(\mathrm{n}=5)$, or multiple UIAs $(\mathrm{n}=8)$.

\section{Demographic Comparisons}

The patients in the EIIC group were significantly older than those in the control group (mean \pm SD: $62.7 \pm 8.3$ years vs $55.9 \pm 10.5$ years, $\mathrm{p}<0.001)$. However, there was no statistically significant between-group differences in patient sex and years of education (Table 2).

\section{Questionnaire Results}

The questionnaire scores for the EIIC group ranged from 7 to 13 (mean $11.9 \pm 1.3$ ) and were significantly higher than those for the controls (range 6-13, mean 10.2 \pm 1.9 ; $\mathrm{p}<0.001)$. The better comprehension of the patients in the EIIC group was especially remarkable as they were significantly older than the patients in the control group (Table 2).

The results of the medical questions on the questionnaire are presented in Table 3. For the EIIC group, the score was $\geq 10$ for 105 patients (95.5\%): 13 for 46 patients (41.8\%), 12 for 31 patients $(28.2 \%), 11$ for 18 patients $(16.4 \%)$, and 10 for 10 patients $(9.1 \%)$. All the medical questions, with the exception of 2 , were correctly answered by the patients with an incidence $>90 \%$. The incorrect answers were most frequently related to 2 questions about treatment indications: question 4 ("Not all cerebral aneurysms need to be treated due to the risk of procedure-related complications" [correctly answered by 87 patients]) and question 6 ("If a patient desires aneurysm treatment due to severe anxiety resulting from harboring a UIA, surgical or endovascular treatment can be applied" [correctly answered by 93 patients]). In contrast, in the control group, only 5 of the 13 questions were correctly answered by the patients with an incidence $>90 \%$.

Regarding the most useful and informative educational method, 90 patients (81.8\%) in the EIIC group selected the verbal information and communication from the attending physician, followed by the video presentation ( $\mathrm{n}$ $=12 ; 10.9 \%)$, information booklets $(\mathrm{n}=7 ; 6.4 \%)$, cartoon book $(n=1 ; 0.9 \%)$, and the Internet $(n=1 ; 0.9 \%)$. In terms of the most important reinforcement of the verbal com-
TABLE 3. Number of patients with correct answers to 13 questions about UIAs*

\begin{tabular}{ccc}
\hline \multicolumn{1}{c}{ Question } & $\begin{array}{c}\text { EllC Group } \\
(\mathrm{n}=110)\end{array}$ & $\begin{array}{c}\text { Control Group } \\
(\mathrm{n}=65)\end{array}$ \\
\hline Pathophysiology & $102(92.7)$ & $39(60.0)$ \\
\hline 1 & $107(97.3)$ & $64(98.5)$ \\
\hline 2 & $109(99.1)$ & $62(95.4)$ \\
\hline 3 & & \\
\hline Treatment indications & $87(79.1)$ & $27(41.5)$ \\
\hline 4 & $107(97.3)$ & $56(86.2)$ \\
\hline 5 & $93(84.5)$ & $39(60.0)$ \\
\hline 6 & & \\
\hline Treatment modalities and alternatives & $100(90.9)$ & $41(63.1)$ \\
\hline 7 & $105(95.5)$ & $61(93.8)$ \\
\hline 8 & $102(92.7)$ & $49(75.4)$ \\
\hline 9 & & \\
\hline Procedural risks & $104(94.5)$ & $55(84.6)$ \\
\hline 10 & & \\
\hline Other management & $104(94.5)$ & $59(90.8)$ \\
\hline 11 & $100(90.9)$ & $56(86.2)$ \\
\hline 12 & & \\
\hline Treatment results & $100(90.9)$ & $59(90.8)$ \\
\hline 13 & & \\
\hline * All data given as number of patients $(\%)$ & & \\
\hline
\end{tabular}

munication, most patients selected the video presentation $(\mathrm{n}=86 ; 78.2 \%)$, followed by the information booklets ( $\mathrm{n}$ $=16 ; 14.5 \%)$, Internet $(\mathrm{n}=7 ; 6.4 \%)$, and cartoon book ( $\mathrm{n}$ $=1 ; 0.9 \%)$.

\section{Years of Education Affecting Patient Comprehension}

For both the EIIC group and the controls, the Pearson correlation analysis showed a positive correlation $(\mathrm{r}$ $=0.232$ for the EIIC group and $r=0.603$ for the control group) between the years of education and the questionnaire score $(\mathrm{p}=0.015$ for the EIIC group, $\mathrm{p}<0.001$ for controls), whereas no correlation was found between the patient age and the questionnaire score.

\section{Discussion}

The current study presents a standardized EIIC process for patients with UIAs. Following this process, most patients exhibited a good comprehension of the natural course of UIAs, recommended treatment with attendant risks and benefits, and reasonable alternatives. The level of comprehension was shown to be affected by the patient's education level (years of education).

An optimal informed consent process can have several positive effects. ${ }^{4,12}$ First, better comprehension leads to augmented autonomy and a greater sense of control for the patient. Second, a basis is provided for a strong and enduring therapeutic alliance between the surgeon and the patient, resulting in better treatment cooperation from patients and fewer medicolegal claims. Third, explaining what to expect intra- and postoperatively has a direct im- 
pact on the quality of health care services. Preoperative disclosure of such information allows the patient to establish psychological defenses for coping with stressful surgical circumstances and prevents the patient from being overwhelmed by the sensations accompanying surgery.

The treatment decision for a UIA is based on a combination of the natural history of the given UIA, the patient's life expectancy, and the treatment risks related to surgical clipping and endovascular coiling. The final treatment decision can be complex and often poorly understood due to the presence of some uncertainty despite a series of management recommendations and guidelines. ${ }^{14,23}$ First, the risk of rupture is estimated based on the angiographic characteristics, including the size, shape, and location of the UIA. Yet, angiograms are contrast column images showing a luminal space rather than depicting the aneurysmal wall, which is the most crucial factor determining the rupture risk. Some patients present with a ruptured aneurysm that is very small in size. Second, a patient's life expectancy cannot be precisely assessed. Third, the risks related to surgical or endovascular treatment vary greatly depending on the individual hospital and surgeon. Such uncertainties are particularly problematic when the patient's condition is borderline between required treatment and observation. A shared acknowledgment of such clinical uncertainties can reinforce the physician-patient relationship, leading to a strong therapeutic alliance. ${ }^{12}$

Optimally, the informed consent discussion should be conducted by the physician who is directly involved in the proposed surgical or endovascular procedure, ${ }^{1,3}$ as relatively unqualified health care professionals such as residents and physician assistants are more likely to present the benefits of the procedure rather than the risks or alternatives. ${ }^{1}$ The current physician-patient interviews were all performed by the attending surgeon or attending interventionist.

The way that information is presented has an important impact on the comprehension level and information retention by patients. Educational intervention in the form of written material, cartoon illustrations, and audiovisual presentation is already known to significantly increase patient comprehension when compared with simple verbal communication. ${ }^{2,5,7,8,20,26}$ However, the proposed EIIC process uses repeated educational intervention in various forms to optimize the patient's understanding before the physician-patient interview and thereby reduce the time and effort involved in the physician-patient discussion.

The transmission of information for the consent process needs to be initiated well in advance of the procedure, allowing the final decision to be made with the time necessary to make a major life decision. Processing the information related to a decision does not finish immediately after the transmission of the information..$^{11,17,21}$ In the proposed EIIC process, the patients were requested to make a decision 2 weeks after the educational process and first physician-patient interview, and if needed the patients were allowed to delay their decision. The short hospital stay for the catheter angiography provided an ideal opportunity to conduct the informed consent process. The surgical or endovascular procedure was then commonly scheduled 1-3 months thereafter.
The natural course of a UIA should be explained based on previous well-designed large studies including the International Study of Unruptured Intracranial Aneurysms (ISUIA) and the Small Unruptured Intracranial Aneurysm Verification (SUAVe) study.9,14,18,22,24,25 Any estimation of the risk of aneurysm rupture should take into account the size, shape, and location of the UIA. ${ }^{13,24,25}$ In addition, the surgical results should be considered when making a decision on whether to proceed with treatment for an individual patient. In a meta-analysis of the mortality and morbidity resulting from surgical clipping of UIAs by Raaymakers et al. ${ }^{19}$ the overall mortality and morbidity was reported as $2.6 \%$ and $10.9 \%$, respectively. However, for patients with non-giant anterior circulation aneurysms, the mortality and morbidity was $0.8 \%$ and $1.9 \%$, respectively.

The aneurysm treatment recommendation should be determined by both an experienced cerebrovascular surgeon and an endovascular interventionist as a multidisciplinary decision, based on the characteristics of the patient and the aneurysm. The surgeon's experience and the treatment outcomes of an individual hospital should also be considered and presented to the patient. ${ }^{6}$ The current neurovascular team treats aneurysms according to the following principles: 1) the treatment modality (surgical vs endovascular) is a joint decision by a vascular surgeon and endovascular interventionist based on previous treatment results; 2) if an aneurysm is amenable to either treatment for complete and safe obliteration of the aneurysm, endovascular treatment is preferred because it is less invasive; and 3) to reduce patient reluctance for surgery in cases with proper indications, minimally invasive surgical procedures are pursued, such as a superciliary keyhole approach.

Although the current study is limited based on a case series from a single institution, a well-designed informed consent process using a variety of educational materials, verbal information from the attending physician, and questionnaire-based supplementary education were found to enhance the patient's level of comprehension about UIAs. In addition, the medical questions included in the questionnaire were limited to the basic knowledge applicable to most patients. Because the advantages and disadvantages of the two treatment modalities (surgical vs endovascular) differ according to the size, shape, and location of the aneurysm and the age and medical condition of the patient, the questionnaire did not include any questions on the differences between the two treatment modalities. However, a comparison of the two treatment modalities, the recommended treatment specific to the patient, and reasons for selecting this treatment modality were all discussed during the physician-patient interview.

\section{Conclusions}

The proposed standardized EIIC process for informed consent-combining patient education using various educational materials, an initial physician-patient interview, answering a questionnaire, and questionnaire-based supplementary education during a second physician-patient interview-was shown to result in good patient compre- 
hension about UIAs. The verbal information and advice from the attending physician was found to be the most informative method of education, while videotaped information was the most effective reinforcement of the verbal communication. The patient's level of comprehension was found to be correlated with his or her educational level (years of education).

\section{Acknowledgments}

This research was supported by a grant from the Korea Health Technology R\&D Project through the Korea Health Industry Development Institute, funded by the Ministry of Health \& Welfare, Republic of Korea (grant no. HI15C0001).

\section{References}

1. Angelos P, DaRosa DA, Bentram D, Sherman H: Residents seeking informed consent: Are they adequately knowledgeable? Curr Surg 59:115-118, 2002

2. Aremu SK, Alabi BS, Segun-Busari S: The role of informed consent in risks recall in otorhinolaryngology surgeries: verbal (nonintervention) vs written (intervention) summaries of risks. Am J Otolaryngol 32:485-489, 2011

3. Bean S, Magwood B, Abdoh AA, Chen J, Hochman J: Informed consent: exploring surgical residents' beliefs, attitudes and practices. Healthc Q 13:68-73, 2010

4. Brenner LH, Brenner AT, Horowitz D: Beyond informed consent: educating the patient. Clin Orthop Relat Res 467:348351, 2009

5. Chan Y, Irish JC, Wood SJ, Rotstein LE, Brown DH, Gullane PJ, et al: Patient education and informed consent in head and neck surgery. Arch Otolaryngol Head Neck Surg 128:1269-1274, 2002

6. Chyatte D, Porterfield R: Functional outcome after repair of unruptured intracranial aneurysms. J Neurosurg 94:417421, 2001

7. Delp C, Jones J: Communicating information to patients: the use of cartoon illustrations to improve comprehension of instructions. Acad Emerg Med 3:264-270, 1996

8. Farrell EH, Whistance RN, Phillips K, Morgan B, Savage $\mathrm{K}$, Lewis V, et al: Systematic review and meta-analysis of audio-visual information aids for informed consent for invasive healthcare procedures in clinical practice. Patient Educ Couns 94:20-32, 2014

9. Güresir E, Vatter H, Schuss P, Platz J, Konczalla J, de Rochement Rdu M, et al: Natural history of small unruptured anterior circulation aneurysms: a prospective cohort study. Stroke 44:3027-3031, 2013

10. Hekkenberg RJ, Irish JC, Rotstein LE, Brown DH, Gullane PJ: Informed consent in head and neck surgery: how much do patients actually remember? J Otolaryngol 26:155-159, 1997

11. Herz DA, Looman JE, Lewis SK: Informed consent: is it a myth? Neurosurgery 30:453-458, 1992

12. Jones JW, McCullough LB, Richman BW: A comprehensive primer of surgical informed consent. Surg Clin North Am 87:903-918, viii, 2007

13. Juvela S, Poussa K, Lehto H, Porras M: Natural history of unruptured intracranial aneurysms: a long-term follow-up study. Stroke 44:2414-2421, 2013

14. Komotar RJ, Mocco J, Solomon RA: Guidelines for the surgical treatment of unruptured intracranial aneurysms: the first annual J. Lawrence pool memorial research symposium-controversies in the management of cerebral aneurysms. Neurosurgery 62:183-194, 2008
15. Kondziolka DS, Pirris SM, Lunsford LD: Improving the informed consent process for surgery. Neurosurgery 58:11841189,2006

16. Krupp W, Spanehl O, Laubach W, Seifert V: Informed consent in neurosurgery: patients' recall of preoperative discussion. Acta Neurochir (Wien) 142:233-239, 2000

17. Lipetz MJ, Bussigel MN, Bannerman J, Risley B: What is wrong with patient education programs? Nurs Outlook 38:184-189, 1990

18. Murphy K: ISAT and ISUIA: the impact on informed consent. Tech Vasc Interv Radiol 8:106-107, 2005

19. Raaymakers TW, Rinkel GJ, Limburg M, Algra A: Mortality and morbidity of surgery for unruptured intracranial aneurysms: a meta-analysis. Stroke 29:1531-1538, 1998

20. Shukla AN, Daly MK, Legutko P: Informed consent for cataract surgery: patient understanding of verbal, written, and videotaped information. J Cataract Refract Surg 38:80-84, 2012

21. Simes RJ, Tattersall MH, Coates AS, Raghavan D, Solomon HJ, Smartt H: Randomised comparison of procedures for obtaining informed consent in clinical trials of treatment for cancer. Br Med J (Clin Res Ed) 293:1065-1068, 1986

22. Sonobe M, Yamazaki T, Yonekura M, Kikuchi H: Small unruptured intracranial aneurysm verification study: SUAVe study, Japan. Stroke 41:1969-1977, 2010

23. Thompson BG, Brown RD Jr, Amin-Hanjani S, Broderick JP, Cockroft KM, Connolly ES Jr, et al: Guidelines for the management of patients with unruptured intracranial aneurysms: a guideline for healthcare professionals from the American Heart Association/American Stroke Association. Stroke 46:2368-2400, 2015

24. Morita A, Kirino T, Hashi K, Aoki N, Fukuhara S, Hashimoto N, et al: The natural course of unruptured cerebral aneurysms in a Japanese cohort. N Engl J Med 366:2474-2482, 2012

25. Wiebers DO, Whisnant JP, Huston J III, Meissner I, Brown RD Jr, Piepgras DG, et al: Unruptured intracranial aneurysms: natural history, clinical outcome, and risks of surgical and endovascular treatment. Lancet 362:103-110, 2003

26. Wollinger C, Hirnschall N, Findl O: Computer-based tutorial to enhance the quality and efficiency of the informed-consent process for cataract surgery. J Cataract Refract Surg 38:655-659, 2012

\section{Disclosures}

The authors report no conflict of interest concerning the materials or methods used in this study or the findings specified in this paper.

\section{Author Contributions}

Conception and design: J Park. Acquisition of data: Son, KS Park, Oh, Kwon, TS Kim, CH Kim. Analysis and interpretation of data: Son, KS Park. Drafting the article: J Park. Reviewed submitted version of manuscript: Kang. Approved the final version of the manuscript on behalf of all authors: J Park. Statistical analysis: Lee. Administrative/technical/material support: Kang. Study supervision: J Park.

\section{Correspondence}

Jaechan Park, Department of Neurosurgery, Kyungpook National University Hospital, 50, Samduk 2-ga, Jung-gu, Daegu 700-721, Republic of Korea. email: jparkmd@hotmail.com. 